\title{
TINJAUAN TENTANG TUGAS DAN WEWENANG BALAI \\ PENGAWAS OBAT DAN MAKANAN (BPOM) DI BATAM \\ TERHADAP PEREDARAN KOSMETIK BERBAHAN \\ KIMIA BERBAHAYA DI KOTA BATAM
}

Alfis Setyawan ${ }^{1}$

Merry Mitha Sari ${ }^{2}$

\begin{abstract}
The purpose of this research is to find out the Duties and authorities of the Food and Drug Supervisory Agency (BPOM) in the supervision of the circulation of cosmetics made from hazardous chemicals in Batam so that it can be known the forms in the implementation of supervision and the factors that impede the supervision process carried out by the Balai POM.

This research method uses a type of empirical juridical research by conducting interviews with Balai POM Officers and interviews with Business Actors and supported by the provisions of the Act relating to the supervision of the circulation of cosmetics made from hazardous chemicals which are then compared with facts that occur and analyzed descriptively.

Duties and authorities obtained by the Central Bureau of Drug and Food Control directly from the Law to examine and act on distribution facilities that commit violations still do not produce public output in accordance with applicable legal regulations, there are obstacles that impede the implementation of supervision and enforcement so that they have not reached conformity between regulations and business actor behavior.
\end{abstract}

Keywords : Drug and Food Control Agency, Duties and Authorities, Cosmetics

\footnotetext{
${ }^{1}$ Fakultas Hukum Universitas Internasional Batam

${ }^{2}$ Fakultas Hukum Universitas Internasional Batam
} 


\section{A. Latar Belakang Masalah}

Kosmetik atau alat rias merupakan suatu bahan erat kaitannya dengan kaum hawa yang pada dasarnya selalu berusaha menunjang penampilan dengan menggunakan produk kosmetik atau produk kecantikan. Meski pada dasarnya kosmetik memiliki jenis yang bervariasi,bahkan bedak bayi dapat dikategorikan kosmetik mengingat memiliki kandungan dari zat kimia tertentu.

Kosmetik biasanya dibuat dari bahan-bahan alami seperti dari tumbuhan atau zat buatan yang diolah sesuai dengan standar kesehatan yang telah ditentukan agar manfaatnya tidak menimbulkan bahaya bagi penggunanya. Namun seiring perkembangan industri kosmetik yang begitu pesat menjadi salah satu faktor akan perkembangan produk kosmetik yang semakin banyak dan beragam. Ditemukan produk kosmetik murah yang adalah produk tiruan bahkan produk tanpa adanya label halal dan tanggal kadaluarsa, biasanya produk jenis ini mengandung bahan kimia berbahaya dalam komposisi pembuatannya.

Adanya kewajiban untuk memberikan izin edar pada kosmetik yang akan diedarkan adalah ketetapan berdasarkan peraturan Peraturan Menteri Nomor 1176/MENKES/PER/VIII/2010 Tentang Notifikasi Kosmetika. Dengan diterbitkannya PERMEN ini kemudian setiap kosmetik yang beredar harus terlebih dahulu memiliki izin edar berupa Notifikasi,hal ini dilakukan demi mencegah beredarnya kosmetik dengan kandungan bahanbahan yang berbahaya.

Notifikasi kosmetika menjadi hal penting bagi para pelaku usaha yang hendak mengedarkan suatu produk kosmetik. Para pemohon izin edar kosmetik ini akan melakukan pengajuan permohonan kepada Kepala Badan,dimana Kepala Badan yang dimaksud adalah pengawas obat dan makanan.

Badan POM dibentuk berdasarkan Peraturan Presiden Republik Indonesia nomor 80 tahun 2017 tentang Badan Pengawas Obat dan 
Makanan (BPOM). Badan Pengawas Obat dan Makanan adalah Lembaga Pemerintah Non Kementrian (LPNK) yang bertanggung jawab kepada Presiden melalui Menteri Kesehatan. Balai POM sebagai lembaga pengawas yang memiliki tugas dan wewenang tertentu dalam bertugas melakukan pengawasan secara berkala demi mencegah adanya peredaran kosmetik berbahan kimia berbahaya agar kesehatan masyarakat turut terjamin. Fenomena tersebut kemudian membawa pertanyaan mengenai peredaran kosmetik berbahan kimia berbahaya yang marak dipasaran, produk kosmetik yang didapatkan dari Luar Negeri menunjukkan bahwa adanya batasan-batasan kewenangan pengawasan Balai POM.

Rangkaian peristiwa tersebut menarik penulis untuk meneliti lebih dalam lagi mengenai peran sebenarnya Balai POM dalam ruang lingkup pengawasan kosmetik yang mengandung bahan berbahaya. Rumusan masalah yang timbul dari latar belakang dapat dirumuskan sebagai berikut:

1) Bagaimanakah tugas dan wewenang Balai Pengawas Obat dan Makanan (BPOM) Kota Batam terhadap peredaran konsmetik berbahan kimia berbahaya di Kota Batam?

2) Apakah hambatan-hambatan yang dihadapi Balai Pengawas Obat dan Makanan Kota Batam dalam melakukan pengawasan terhadap peredaran kosmetik berbahan kimia berbahanya di Kota Batam?

\section{B. Metode Penelitian}

Jenis penelitian yang digunakan dalam penelitian ini daripada melihat langsung pada hukum yang mengatur distribusi kosmetik berbahaya, juga melihat secara langsung apa yang terjadi di lapangan (masyarakat). Penggunaan metode empiris ini karena informasi yang dibutuhkan ada dalam penyebaran informasi yang tidak memiliki nilai angka adalah data yang diperoleh dari wawancara dengan Petugas Balai Pengawas Obat Dan Makanan (BPOM). Oleh karena itu dalam hal ini perolehan informasi yang akurat begitu diperlukan dengan menemukan fakta dan secara langsung 
mewawancarai Pelaku Usaha, kemudian akan menggambarkan objek dalam sistem studi dan daftar semua masalah yang terkait dengan objek dalam penelitian dan kemudian mengatur data yang diperoleh berdasarkan analisis.

Data sekunder terdiri dari bahan hukum primer, bahan hukum sekunder dan bahan hukum tersier ${ }^{3}$. Adapun data yang Penulis gunakan adalah sebagai berikut:

1) Bahan Hukum Primer berupa hukum positif yaitu Undang-Undang Nomor 08 Tahun 1999 Tentang Perlindungan Konsumen, UndangUndang Nomor 32 Tahun 2009 Tentang Kesehatan, Peraturan Menteri Kesehatan Republik Indonesia 1176/MENKES/PER/VIII/2010 Tentang Notifikasi Kosmetika, Peraturan Kepala Badan Pengawas Obat dan Makanan Republik Indonesia nomor 12 tahun 2018 Tentang Organisasi dan Tata Kerja Unit Pelaksana Teknis di Lingkungan Badan Pengawas Obat dan Makanan, Peraturan Kepala Badan Pengawas Obat Dan Makanan (BPOM) Nomor HK 03.1.23.12.11.10052 Tahun 2011 Tentang Pengawasan Produksi dan Peredaran Kosmetik.

2) Bahan Hukum Sekunder Bahan hukum sekunder yang diguanakan seperti rancangan peraturan, buku- buku hukum yang berkaitn dengan permasalahan, hasil penelitian atau karya tulis dari kalangan hukum.

3) Bahan Hukum Tersier, yang terdapat dalam penelitian ini sebagian besar berasal dari Kamus Besar Bahasa Indonesia dan Kamus Hukum

Pengumpulan data akan dilakukan melalui proses wawancara ddengan narasumber dan studi pustaka sebagai penunjang data yang diperoleh dari hasil wawancara kemudian akan dilakukan analisa menggunakan konsep kualitatif deskriptif yang akan menguraikan hasil penelitian kedalam paragraf deskriptif.

\footnotetext{
${ }^{3}$ Ronny Hanitijo Soemitro, "Metodologi Penelitian Hukum dan Jurimetri", (Jakarta: Ghalia Indonesia) 2001, hlm 10.
} 


\section{Hasil Penelitian dan Pembahasan}

Balai Pengawas Obat dan Makanan (BPOM) adalah Lembaga pemerintah yang bertugas menjalankan Undang-Undang dalam hal pengawasan di bidang obat dan makanan khususnya kosmetika. Tugas pengawasan Balai POM dimulai saat sebalum produk beredar (pre market) dan saat produk sudah beredar (post market) oleh karena itu setiap produk kosmetik yang beredar di Indonesia wajib mendaftarkan produknya agar memiliki nomor izin edar sebagai legalitas peredaran kosmetika sesuai standar kualitas, keamanan dan kesehatan.

Tugas Balai POM yang tidak hanya terbatas pada pengawasan bahkan lebih dari itu, wewenang Balai POM untuk melakukan penindakan terhadap para Pelaku Usaha yang melakukan pelanggaran ${ }^{4}$ berdasarkan Peraturan Kepala Badan POM Nomor 12 Tahun 2018 Tentang Organisasi dan Tata Kerja Unit Pelaksana Teknis di Lingkungan Badan Pengawas Obat dan Makanan

\section{Bentuk Tugas Dan Tanggung Jawab Balai Pengawas Obat Dan Makanan (BPOM) Terhadap Peredaran Kosmetik Berbahan}

\section{Kimia Berbahaya}

\section{a. Pengawasan}

Peraturan Kepala Badan POM Nomor HK 03.1.23.12.11.10052 tentang Pengawasan Produksi dan Peredaran Kosmetika pada pasal 6 menunjukkan bahwa pengawasan berbentuk suatu pemeriksaan baik secara rutin yang dilakukan untuk memastikan produk dan penyedia sarana masih mengedarkan produk sesuai mutu dan kualitas kesehatan yang baik. Sedangan pemeriksaan khusus lebih condong kepada bentuk tindak lanjut dari upaya pengawasan jika terindikasi adanya pelanggaran.

\footnotetext{
${ }^{4}$ Indonesia, Peraturan Kepala Badan POM, PerKa Nomor 12 Tahun 2018
} 
Target dan sasaran pengawasan Balai POM meliputi importir, agen/distributor, toko/pengecer, klinik kecantikan, salon dan sarana distribusi kosmetik lainnya. Namun Balai POM terfokus pada importir dan distributor dikarenakan peredaran produk kosmetik melalui sarana distribusi kosmetik seperti distributor kosmetik dan atau importir.

Pada pengawasan pre market Balai POM meletakkan sasaran pengawasan ke Industri Kosmetika dan Importir, dikarenakan di Batam dan Kepulauan Riau tidak tersedia sarana Produksi sehingga Pengawasan dilakukan ke sarana distribusi seperti Distributor kosmetik dan toko kosmetik. Pengawasan pre market yang dilakukan oleh Balai POM adalah penerapan prinsip pengawasan preventif, pengawasan dilakukan dengan tujuan untuk meminimalisir terjadinya kesalahan dalam hal ini pencegahan beredarnya produk kosmetik berbahan kimia berbahaya.

Tindakan pengawasan yang dilakukan oleh Balai POM merupakan langkah pencegahan terhadap masuknya produk kosmetika berbahan kimia berbahaya ke Batam melalui pemegang sarana distribusi, khusunya distributor. Distributor di Batam dalam proses pemasukan barang dapat mencapai jumlah dan value yang cukup besar karena cakupan peredarannya tidak hanya di Batam melainkan juga ke daerah lain di Kepulauan Riau.

Pada pengawasan pre market sesungguhnya peraturan perundangan menjadikan Balai POM untuk memberikan informasi kepada pemegang sarana produksi untuk mendaftarkan produk yang di produksi agar sesuai dengan standar mutu, kemanan dan kesehatan. Penentuan standar mutu dengan melakukan uji sampel produk sebelum memberikan nomor izin edar atau sertifikasi produk kosmetika untuk mencegah masuknya 
kandungan berbahaya dalam produk kosmetika yang akan diproduksi.

Langkah pemberian informasi bagi pemegang sarana produksi dalam hal ini importir belum efektif untuk mencegah beredarnya produk kosmetika berbahan kimia berbahaya dikarenakan belum tercatat adanya pemegang sarana produksi di Batam sehingga proses beredarnya kosmetik berbahan kimia berbahaya berasal dari luar Batam. Penerapan prinsip pengawasan represif dilakukan dalam pengawasan post market yang terjadi setelah produk kosmetik telah siap untuk dikonsumsi dan telah beredar terhambat oleh kurang luasnya pelaksanaan pemeriksaan yang dilakukan petugas Balai POM.

\section{b. Penindakan}

Pengawasan post market berprinsip pengawasan represif demi menanggulangi kesalahan dan pelanggaran yang terjadi setelah produk kosmetik beredar di pasaran. Pelanggaran yang terjadi disebabkan dari lalai nya pengawasan terhadap masuknya poduk kosmetika dari berbagai jalur misalnya dari pelabuhan. Fakta yang ditemukan berdasarkan keterangan dari Ibu Eni sebagai seorang karyawati salah satu distributor kosmetik di Batam mengenai pemasukan kosmetika yang cenderung tanpa pemeriksaan yang ketat dikarenakan kuantitas produk yang sedikit, namun masuk nya produk yang mulai dari sedikit itu tetap memberikan sebuah kebebasan bagi Pelaku Usaha untuk tetap memasukkan produk kosmetik berbahan kimia berbahaya tanpa adanya filter dari petugas terkait.

Inspeksi ke sarana distribusi oleh Balai POM tidak memiliki jangka waktu tertentu bahkan lebih condong benar-benar hanya melakukan pengawasan secara intensif ke distributor saja tanpa memperhatikan toko kosmetik atau pengecer. Dalam peraturan 
perundangan dijelaskan bahwa pengawasan Balai POM tidak hanya terbatas pada importir dan distributor saja melainkan harus menyeluruh, hal ini sebagai salah satu faktor masih ditemukannya produk kosmetik yang tidak memenuhi syarat di pasaran. Adanya sanksi administratif yang dapat diberikan kepada pelaku pelanggaran adalah suatu bentuk toleransi Balai POM untuk memberikan kesempatan bagi Pelaku Usaha agar melakukan perubahan. Penerapan sanksi secara administratif ini salah satunya pemberhentian izin poduksi, pemusnahan produk dan penyitaan produk tanpa izin edar yang secara langsung menghentikan proses peredaran kosmetik berbahan kimia berbahaya.

\section{c. Pembinaan}

Peraturan Presiden Nomor 80 Tahun 2017 tentang Unit Pelaksana Teknis di Lingkungan Badan POM memberi tugas untuk melangsungkan kegiatan Komunikasi Informasi dan Edukasi (KIE) sebagai langkah dalam memberikan perlindungan kepada Konsumen. Perlindungan yang diberikan dengan cara menumbuhkan kesadaran dalam diri individu untuk mengetahui dampak dari penggungaan kosmetik berbahan kimia berbahaya.

Pemberian edukasi atau pembinaan baik kepada konsumen maupun kepada para pelaku usaha selain menambahkan ilmu pengetahuan tentang produk kosmetika yang aman untuk dikonsumsi oleh masyarakat, juga sebagai peningkatan kesadaran akan penggunaan produk yang rasional. Menumbuhan Konsumen dengan kesadaran dan tingkat pengetahuan yang tinggi terhadap mutu dan kegunaan suatu produk, di satu sisi dapat membentengi dirinya sendiri terhadap penggunaan produk-produk yang tidak memenuhi syarat dan tidak dibutuhkan sedang pada sisi lain akan mendorong produsen untuk ekstra hati-hati dalam menjaga kualitasnya.. 
Output yang terjadi dalam masyarakat hanyalah golongan terpelajar saja yang berpartisipasi dalam kegiatan KIE ini, bahkan masyarakat awam seperti ibu rumah tangga dan Pelaku Usaha berbentuk toko kosmetik tidak menjangkau kegiatan yang dilakukan oleh Balai POM karena Pemberian informasi dan edukasi tidak dilaksanakan di berbagai media bahkan bersifat pasif yaitu menunggu masyarakat untuk datang ke Balai POM atau ULPK Balai POM.

\section{Faktor-Faktor yang Menghambat Balai POM dalam Melakukan Pengawasan Kosmetik di Kota Batam}

\section{a. Faktor Internal}

Sarana distribusi kosmetik yang semakin bertambah dirasa kurang maskimal jika tidak di iringi dengan betambahnya jumlah sumber daya manusia agar lebih memadai. Peran serta pemerintah dalam menanggulangi peredaran kosmetik berbahaya sangat diperukan sehingga diharapkan dengan adanya bantuan dari pihak lain dapat memaksimalkan kinerja Balai POM setidaknya menjangkau pengawasan perdaran kosmetik berbahan kimia berbahaya ke sarana distribusi yang ada di Batam.

Jumlah pegawai Balai POM yang masih belum memadai, tercatat pada tahun 2018 ada sebanya 43 (empat puluh tiga) orang pegawai yang diataranya 3 (tiga) orang masih menempuh pendidikan. Pada bagian penindakan sendiri hanya terdapat 4 (empat) orang, dan dinilai masih kurang efektif untuk terus menjalankan tugas pengawasan secara rutin dan berkala ke sarana distribusi kosmetik yang ada. ${ }^{5}$

Permasalahan kuantitas masih menjadi kendala yang utama dalam hal pelaksanaan pengawasan yang dilakukan seksi pemeriksaan dan penindakan yang biasanya dibantu oleh seksi

\footnotetext{
${ }^{5}$ Laporan Tahunan Balai Pengawas Obat dan Makanan (BPOM) di Batam tahun 2018
} 
jabatan fungsional. Penabahan SDM tidak hanya mengaharapkan adanya penambahan kuantintas jumlah pegawai saja, lebih dari itu Balai POM mengharapkan penambahan SDM turut menambah kualitas pegawai sehingga mampu meningkatkan kualitas kinerja Balai POM dalam pelaksanaan pengawasan, penindakan dan pembinaan.

Beban kerja yang ditanggugn oleh Balai POM bukan hanya di Wilayah Batam saja, lebih dari itu perlu dilakukannya ispeksi ke sarana distribusi yang ada diluar Batam sehingga jumlah petugas begitu diperlukan untuk membegi-bagi ke wilayah lainnya dalam hal penerapan pengawasan dan penindakan. Terhadap kualitas pegawai Balai POM dapat dilihat dari segi pendidikan yang dimiliki dengan kesesuaian jabatan kerja yang dipegang, beberapa pegawai dilihat tidak memiliki kesesuaian antara latar belakang pendidikan dengan bidang keahliannya sehingga dapat menimbulkan kurangnya kompetensi yang mendukung untuk menerapkan suatu kebijkan yang ada.

\section{b. Faktor Eksternal}

Para Pelaku Usaha yang masih belum jera terhadap penindakan atas larangan peredaran produk dengan bahan kimia berbahaya dipengaruhi berbagai hal salah satunya dalah penerapan sanksi pidana terhadap para pelanggar. Untuk suatu kasus tindak pidana terkait kosmetik, pengadilan menetapkan hukuman terhadap perkara tersebut hukuman penjara selama 9 (sembilan) bulan yang dirasa tidak sesuai mengingat terpidana menyimpan dan mengedarkan kosmetik tanpa izin edar dengan harga nominal yang tidak sedikit. ${ }^{6}$

Pemerintah masih belum menganggap bahwa peredaran kosmetik berbahan kimia berbahaya adalah suatu kejahatan besar,

\footnotetext{
${ }^{6}$ Hasil Wawancara dengan Seksi Pengawas Makanan dan Farmasi Balai Pengawas Obat dan Makanan di Batam pada tanggal 14 April 2019
} 
seingga dampak hukuman bagi para pelaku kejahatan masih tergolong ringan. Penggunaan kosmetik berbahan imia berbahaya justru akan membawa dampak dalam jangka waktu lima atau sepuluh tahun mendatang.

Pelaku usaha yang memilih untuk tetap menjual produk tanpa izin edar kemudian melakukan bermacam cara untuk mengelabui petugas pengawas. Kurangnya langkah pendekatan dan sosialisasi kepada para Pelaku Usaha menjadi kelalaian Balai POM untuk membangun relasi antara Pelaku Usaha dengan Balai POM.Pengawasan Produk kosmetik yang mengandung bahan kimia berbahaya disimpan ditempat yang letaknya sedikit jauh dari lokasi sarana distribusi, Pelaku Usaha meninggalkan tempat saat petugas mendatangi lokasi atau menutup gerai sementara saat petugas melakukan kegiatan pemeriksaan. Tindakan Pelaku Usaha yang menghindari petugas pengawasn itu yang membuat Balai POM kesulitan dalam melakukan pemeriksaan sarana distribusi membawa dampak peredaran kosmetik tanpa izin edar yang makin marak.

Terselenggaranya pengawasan peredaran kosmetik oleh sebuah institusi atau departemen yaitu tidak hanya semata-mata sebagai bentuk penilaian akan legalitas suatu produk kosmetik yang akan dikonsumsi oleh masyarakat, namun sebagai suatu sarana untuk menilai kinerja dan sebagai sarana perbaikan dari institusi atau departemen yang berwenang. Oleh karena itu, pengawasan peredaran kosmetik diselenggarakan secara berkala sesuai dengan tugas dan tanggung jawab institusi atau departemen yang berwenang menurut undang-undang

Pelaku Usaha memandang Balai POM sebagai momok yang menakutkan karena akan memimbulkan berbagai dampak kerugain secara finansial dan ketakutan untuk menerima sanksi jika terbukti melakukan pelangaran. Oleh karena itu melakukan 
proses kunjungan ke sarana distribusi, mengundang Pelaku Usaha untuk turut hadir dalam kegiatan yang diadakan Balai POM mnjadi salah satu cara untuk mengenalkan Balai POM kepada publik agar diketahui tugas dan kebijakannya dalam menanggulangi peredaran ksometik berbahan kimia berbahaya.

\section{Kesimpulan}

Dari hasil penelitian yang telah didapatkan ,maka dapat diambil kesimpulan sebagai berikut:

1. Balai POM dengan tugas dan wewenangnya sebagai lembaga yang mengawasi peredaran kosmetik berbahan kimia berbahaya berbentuk pengawasan sebagai langkah awal untuk menyaring dan memilah produk kosmetik yang akan beredar harus sesuai dengan standar mutu, kemanan, dan kemanfaatan. Penindakan sebagai suatu penanggulangan atas terjadinya pelanggaran dengan menerapkan hukuman sebagai suatu resiko atas pelanggaran yang dilakukan. Pembinaan untuk menumbuhkan kesadaran untuk melindungi diri sendiri dari produk kosmetik berbahan kimia berbahaya.

2. Permasalahan yang menghambat kinerja pengawasan yakni kuantitas pegawai Balai POM yang tidak sesuai dengan beban kerja yang memiliki tugas tidak hanya sebagai pengawas namun menindak dan melakukan pembinaan kepada masyarakat. Kualitas pegawai Balai POM tentunya tidak dinilai dari latar belakang pendidikan namun dari pengalaman dan kesesuaian antara pendidikan dan komsetensi atau jabatan yang dipegangnya. Tanggung jawab dari Pelaku Usaha yan masih minim karena cenderung menganggap Balai POM sebagai aparatur negara yang menimbulkan kerugian bagi Pelaku Usaha sehingga cenderung dihindari, hal inilah yang menajadi potesi terus berlangsungnya peredaran kosmetik berbahan kimia berbahaya. 


\section{Daftar Pustaka}

\section{Buku}

Hanitijo Soemitro, Ronny. Metodologi Penelitian Hukum dan Jurimetri. Jakarta: Ghalia Indonesia.2001

\section{Peraturan Perundang-Undangan}

Indonesia. Peraturan Kepala Badan Pengawas Obat dan Makanan (BPOM). Tentang Pengawasan Produksi dan Peredaran Kosmetika Nomor HK 03.1.23.12.11.10052 Tahun 2011

Indonesia. Peraturan Kepala Badan Pengawas Obat dan Makanan (BPOM). Nomor 12 Tahun 2018 Tentang Organisasi dan Tata Kerja Unit Pelaksana Teknis di Lingkungan Badan Pengawas Obat dan Makanan 